\title{
11ejpec
}

\section{Fusões e aquisições no Brasil e a desnacionalização da produção nos anos 2000}

\section{Cesar Tirso}

Graduando em Ciências Econômicas pelo IERI/UFU

E-mail: cesartirso1@gmail.com

\section{Michele Polline Veríssimo}

Professora do Instituto de Economia e Relações Internacionais da Universidade Federal de Uberlândia (IERI/UFU)

E-mail: micheleverissimo@ufu.br

Resumo: Este artigo tem como objetivo analisar as características do processo de fusões e aquisições (F\&A) no Brasil, buscando identificar uma possível relação com a desnacionalização da produção nos anos 2000. Neste sentido, o trabalho efetiva inicialmente uma contextualização teórica do tema e descreve o perfil nacional sobre as operações de F\&A realizadas no período. Posteriormente, analisa-se o investimento estrangeiro direto (IED) juntamente com a desnacionalização da produção a fim de buscar uma correlação entre tais variáveis. As evidências sugerem que as F\&A não são influenciadas de forma significativa pelo IED, portanto, acredita-se que tais operações não são diretamente relacionadas com a desnacionalização da produção.

Palavras chaves: Fusões e Aquisições; investimento direto estrangeiro; desnacionalização.

\begin{abstract}
This paper aims to analyze the characteristics of the mergers and acquisitions (M\&A) process in Brazil, seeking to identify a possible relationship with the production denationalization in the 2000s. In this way, the work initially has a theoretical contextualization about the theme, and describes the national profile on M\&A operations carried out in the period. Subsequently, foreign direct investment (FDI) is analyzed along with the production denationalization in order to seek a correlation between such variables. The evidences suggest that M\&A are not significantly influenced by FDI, so it is believed that M\&A operations are not directly related to the production denationalization.
\end{abstract}

Key words: Mergers and acquisitions; foreign direct investment; denationalization. JEL Code: $L 10$ 


\section{INTRODUÇÃO}

No Brasil, o uso da estratégia de Fusões e Aquisições (F\&A) foi recorde no ano de 2014, com cerca de 820 operações realizadas, que colocaram aproximadamente US\$ 108 bilhões em circulação, segundo dados da PwC (2015). Ainda de acordo com a mesma fonte, em 2015, mesmo com queda em relação ao ano anterior, foram realizadas 773 operações, movimentando cerca de US\$ 35 bilhões. Com a redução nas transações domésticas, as operações estrangeiras têm obtido destaque, principalmente aquelas que se referem a empresas brasileiras comprando estrangeiras, onde se teve o número de intervenções mais elevado nos últimos cinco anos, de acordo com o boletim da KPMG (2015b).

Apesar dos números serem positivos, estes poderiam ser ainda melhores, uma vez que a valorização do dólar tenderia a tornar mais atrativo a vinda dos investidores estrangeiros dispostos a aumentar o investimento no Brasil. Porém, de acordo com a PwC (2015), as incertezas com o mercado e a instabilidade política reduzem a credibilidade nacional e, por consequência, aumentam os riscos de uma operação de F\&A.

O estudo sobre F\&A no Brasil é de suma importância, uma vez que, observando o cenário atual, em que a economia vem apresentando queda no seu Produto Interno Bruto (PIB), há um aumento do número de empresas com dificuldades financeiras. Como parte de uma estratégia para melhorar seus resultados contábeis, tais empresas buscam vender ativos, ou ainda fazer venda direta, com o objetivo de quitar suas dívidas gerais. Logo, as empresas que possuem bases financeiras sólidas tendem a tirar proveito desse momento de fragilidade nacional.

Destarte, este artigo pretende analisar o possível impacto que das operações de F\&A sobre o processo de desnacionalização da produção no Brasil, pois, além de diminuir a criação de novos estabelecimentos - os chamados investimentos greenfield -, considera-se mais seguro investir em um sistema de operação já existente (brownfield) do que criar uma capacidade nova de produção.

Com isso, pretende-se responder à seguinte pergunta: O aumento das operações de F\&A recentes no país está relacionado ao processo de desnacionalização da produção? A hipótese inicial é a de que o aumento das operações de $F \& A$, principalmente do estilo cross border, tem uma influência direta na desnacionalização da produção. Como esse modelo de operação está superando as F\&A domésticas durante os anos 2000, é possível que a desnacionalização da produção esteja ocorrendo.

O artigo está dividido em cinco seções, incluindo esta introdução. A segunda seção expõe a base teórica para se entender o processo de $\mathrm{F} \& A$ em conjunto com a desnacionalização. A terceira seção descreve o cenário das F\&A no Brasil. A quarta seção analisa a influência e os resultados do investimento direto estrangeiro (IDE) neste tipo de operação. A última seção sistematiza as considerações finais do trabalho. 


\section{REFERENCIAL TEÓRICO}

Esta seção apresenta os aspectos teóricos que fundamentam o artigo. Para isso, a primeira subseção define e explica as motivações da utilização da estratégia de $F \& A$. A segunda subseção analisa a literatura que trata do processo de desnacionalização da produção.

\subsection{PRINCIPAIS CONCEITOS SOBRE F\&A}

A estratégia de F\&A pode ser classificada como uma ação de diversificação com vistas ao crescimento, em que a empresa busca novas formas de atuação em termos de mercados geográficos (que podem ser distintos da sua área original de atuação, ou não) e linha de produtos. Levando em consideração as premissas do sistema econômico capitalista, é preciso estar sempre buscando formas de elevar os resultados finais da empresa uma vez que uma firma tem a "obrigação" de crescer para conseguir manter seu poder de mercado em relação aos concorrentes (KUPFER, 2002).

O processo de fusão é caracterizado como a combinação de duas ou mais empresas que legalmente deixam de existir para formar uma nova firma com uma identidade diferente, onde nenhuma das empresas participantes desse processo prevalece. Já a aquisição acontece quando a compra da totalidade de uma empresa se dá sobre outra, de forma que a comprada deixa de existir legalmente, mantendo assim somente a identidade da firma que realizou a compra (HITT, 2008).

Deste modo, é possível diferenciar ambos os processos no ponto onde a fusão, quando consolidada, cria uma nova firma, enquanto na aquisição uma delas deixa de existir. Hitt (2008) argumenta que, nas fusões, as firmas tendem a ser do mesmo setor, logo, possuem o mesmo produto final, enquanto nas aquisições é comum perceber a negociação entre firmas de setores diferentes.

A estratégia de F\&A pode ser classificada pelas características das empresas que realizam tal operação. A primeira classificação existente se refere às $F \& A$ horizontais, que ocorrem entre empresas que ofertam o mesmo produto ao mercado, ou seja, entre concorrentes. Essa operação tem como objetivo criar economias de escala e de escopo, facilitando assim a entrada em novas regiões, além de elevar o market-share (SANDRONI, 2005; HITT, 2008).

As $F \& A$ verticais acontecem entre empresas que produzem produtos que se encontram dentro do mesmo processo produtivo, podendo tal operação ser realizada de forma upstream, que é a entrada em estágios anteriores do processo de produção, ou downstream, que é a entrada em estágios posteriores. O objetivo dessa estratégia consiste em ampliar o controle sobre as atividades que compõem a cadeia produtiva, facilitando a distribuição dos produtos, diminuindo o custo total da produção e aumentando a segurança empresarial (SANDRONI, 2005; HITT, 2008; KUPFER, 2002).

O processo de F\&A em conglomerado é caracterizado pelo envolvimento entre várias empresas que participam dos mais diferentes setores do mercado. Neste caso não existe relação entre as linhas de produção das firmas participantes. Sua realização pode ter como objetivo o aproveitamento em relação a novas oportunidades de investimento, 
tendo em vista uma especialização extremamente específica da empresa em seu setor, que a impede de estabelecer sinergias com outras atividades. Essa estratégia pode ser motivada pelo avanço das atividades de planejamento que conseguem localizar algum tipo de sinergia em setores que aparentemente são desconectados. Além disso, esse tipo de F\&A é a mais segura quando se avalia a questão das leis federais sobre concorrência, pois não implicam necessariamente em aumento do poder de mercado e concentração (SANDRONI, 2005; KUPFER, 2002).

A última classificação é a F\&A concêntrica, que ocorre entre empresas ou indústrias que não trabalham com produtos ou serviços similares, porém apresentam algum tipo de sinergia, seja financeira, produtiva ou gerencial, entre as diversas atividades. Essa operação acontece com o objetivo de diminuir os custos de produção e os riscos, podendo também permitir a entrada em novos mercados e conseguir de forma rápida o know-how necessário. Normalmente o objetivo deste tipo de operação é ter acesso a ativos complementares ou competências essenciais de outras firmas (BORGES; COSTA, 2008).

Também é possível classificar as operações de F\&A pela origem do capital na transação. Utilizando a classificação feita pela KPMG, as F\&A podem ser caracterizadas como "domésticas", quando envolve duas empresas da mesma nacionalidade, e como "cross border", quando o processo envolve empresas de países diferentes.

As F\&A do tipo cross border podem ser decompostas em cinco diferentes tipos. 0 número um (cb1) ocorre quando uma empresa de capital majoritariamente estrangeira adquire, de brasileiros, capital de uma empresa instalada no Brasil. A número dois (cb2) é caracterizada pelo momento em que uma empresa de capital majoritário brasileiro adquire, de estrangeiros, capital de empresa estabelecida no exterior. O número três (cb3) ocorre quando uma empresa de capital majoritário brasileira adquire, de estrangeiros, capital de uma firma estabelecida no Brasil. A número quatro (cb4) é rotulada quando empresa de capital majoritariamente estrangeira adquire, de estrangeiros, capital de empresas instaladas no Brasil, e, por fim, a número cinco (cb5) consiste em empresa de capital principalmente estrangeiro adquirindo, de brasileiros, capital de uma firma localizada no exterior.

O processo de F\&A começou a ser uma estratégia frequentemente utilizada a partir do final do século XVIII e início do século XIX dentro do contexto de acumulação e concentração de capitais. Alguns especialistas no assunto tratam essa operação como um acontecimento de altas e baixas realizações de acordo com período estudado, chamando assim de "ondas de fusão".

Considerando como base o mercado norte americano, pode-se separar os picos da estratégia de F\&A em ondas, sendo a primeira no final dos anos 1890 e início de 1900, quando aconteceu a tentativa de as empresas criarem monopólios em seus respectivos setores, criando os trusts, que possuíam uma extrema força horizontal. O governo americano criou assim a Lei Antitruste Sherman para tentar proteger o consumidor dos possíveis conglomerados que estavam para surgir.

A segunda onda aconteceu por volta de 1926, onde vigiadas pela lei antitruste, as empresas deixaram de tentar formar monopólios para formar oligopólios, que foram 
impulsionados pelos avanços econômicos e tecnológicos dados pelo "boom" após a primeira guerra mundial. Tal operação se manteve em alta até 1929, com a chegada da crise internacional (CORDEIRO, 2015; SALGADO, 2010).

A terceira onda ficou caracterizada pela diversificação das empresas que realizavam essa estratégia criando um grande mercado de conglomerados, uma vez que a lei antitruste diminuiu as fusões verticais e horizontais. Essa onda durou de 1965 até 1969, devido ao fraco desempenho das firmas.

A quarta onda, que ocorreu na década de 1980, ficou marcada pelas aquisições hostis, que, segundo Sandroni (2005), é uma "situação na qual uma empresa adquire outra, sem consentimento prévio por meio de uma oferta (hostil) muito elevada de compra de ações e difícil de recusar por parte dos acionistas". Além disso, esse período ficou marcado pelo tamanho das empresas-alvo, sendo que alguns autores classificam esse período como "onda de megafusões" (CORDEIRO, 2015; SALGADO, 2010).

A quinta onda foi marcada pelos resultados da quarta onda, assim grande parte das fusões foram feitas de forma estratégica avaliando benefícios no longo prazo. Também se pode dizer que ela foi a primeira onda realmente internacional, ocorrendo no período de 1992 até o estouro da bolha do mercado de ações em 2000.

A sexta onda pode ser caracterizada pela grande quantidade de dólares no mercado, em vista que os EUA mantiveram baixas taxas de juros para estimular a economia. Além disso, o mercado de capitais cresceu deixando uma grande quantidade de dinheiro disponível. O fim dessa onda, que se iniciou em 2001, ocorreu em 2007 com a eclosão da crise do subprime (CORDEIRO, 2015).

Em linhas gerais, a grande vantagem na estratégia de F\&A é a possibilidade de eliminar ou reduzir os riscos gerais de entrada de uma empresa em um novo mercado, sejam eles tecnológicos ou financeiros. Além disso, as empresas que realizam essa operação criam nova posição no mercado, diminuindo o poder da concorrência, e obtendo um domínio maior sobre a produção e a distribuição de suas mercadorias. É importante destacar também que as $F \& A$ tendem a ser operações que podem incorporar empresas dentro de um mercado já existente. Neste caso, o processo permite a quebra de barreiras à entrada em determinada atividade. Porém, assim que fixadas no ramo, o compartilhamento dos ativos entre as empresas envolvidas fortalece as barreiras existentes ou criam novas barreiras, dificultando a entrada de novos concorrentes (KUPFER, 2002).

\subsection{A DESNACIONALIZAÇÃO DA PRODUÇÃO PELAS F\&A}

A desnacionalização pode ser caracterizada, segundo Sandroni (2005), por "um processo pelo qual grupos ou empresas estrangeiras adquirem o controle de uma parcela crescente da economia de um país". Esse ato pode acontecer de três formas: a primeira é a compra de empresas nacionais por grupos estrangeiros, que pode ser considerado o de menor importância, uma vez que os antigos proprietários de empresas nacionais tendem a conservar seus patrimônios para poder investir em novas firmas dentro do mesmo território. O segundo modo é a concorrência das firmas internacionais sobre as 
nacionais, retirando-as do mercado. E a terceira é a ocupação de setores novos ou dinâmicos da economia, onde as multinacionais ocupam áreas com investimentos relativamente baixos.

É importante salientar que o termo desnacionalização não é sinônimo de internacionalização, pois a primeira é obrigatoriamente um processo de entrada de capital estrangeiro na região observada, enquanto a segunda pode ser uma expansão das fronteiras de mercado sem a perda da participação nacional na produção (via exportações ou licenciamento de ativos, por exemplo). Logo, pode-se dizer que o processo de desnacionalização é uma internacionalização, porém não necessariamente a internacionalização configura desnacionalização.

A desnacionalização é um processo considerado complexo e dependente principalmente dos investimentos vindos do exterior, uma vez que estes fazem concorrência com a produção nacional. Assim, para se analisar esse acontecimento de diminuição da participação da produção nacional é preciso verificar o seu principal influenciador, o investimento estrangeiro direto (IED) ${ }^{1}$.

Dentre as explicações sobre a motivação da realização do IED, destaca-se "o modelo de Dunning" (AMAL; SEABRA, 2007), segundo o qual uma empresa multinacional tem maiores benefícios quando se observa três detalhes: as vantagens de propriedade (ownership); as vantagens de localização (location); e as vantagens de internacionalização (internalization) (CASTRO ET AL., 2014).

As vantagens de propriedade podem ser explicadas como o benefício exclusivo da empresa, onde é atribuída uma conveniência desta sobre seus concorrentes, o que pode ser feito por forma de tecnologias ou patentes, as quais configuram inicialmente barreiras à entrada, mesmo que temporárias. As vantagens de localização estão relacionadas com os bens disponíveis em determinados locais, tais como recursos naturais, que incentivam o investimento. E, por fim, as vantagens de internacionalização, que, quando existentes os dois benefícios anteriores, é necessário avaliar se a firma decide se internacionalizar observando os rendimentos líquidos que podem ser obtidos (RODRIGUES, 2009; CASTRO ET AL.,2014).

Dunning também explora algumas subdivisões para explicar os determinantes do IED ao mercado internacional. A primeira classificação é chamada de resource seeking (busca por recursos), onde existe o objetivo de obter determinados recursos que acabam "facilitando" a busca por lucro, como mão de obra barata. A segunda é o market seeking (busca por mercados), que analisa os mercados considerados possíveis entrantes para conseguir projetar o crescimento do consumo e ver se é viável sua instalação. A terceira é a efficiency seeking (busca por eficiência), que procura economias de escala e escopo principalmente. E, por fim, temos a strategic asset seeking (busca por ativos estratégicos),

\footnotetext{
${ }^{1}$ O Investimento Estrangeiro Direto (IED) envolve a movimentação de capitais internacionais para propósitos específicos de investimento, quando empresas ou indivíduos no exterior criam ou adquirem operações em outro país. O IED engloba "fusões e aquisições, construção de novas instalações, reinvestimento de lucros auferidos em operações no exterior e empréstimos intercompany (APEX BRASIL, 2017).
} 
que intenciona obter recursos ou ativos financeiros, sendo que, teoricamente, esta é a principal categoria onde temos as ações de F\&A de empresas (CASTRO ET AL., 2014).

É importante destacar que a estratégia de F\&A está se tornando cada vez mais recorrente devido ao fato de ser considerado mais fácil adquirir meios de produção do que tentar criar uma estrutura produtiva nova. Levando isso em consideração, dois conceitos de investimento estrangeiro são de suma importância: o primeiro é o greenfield project, onde é realizado um investimento em uma estrutura produtiva nova, inexistente anteriormente, e o segundo é o brownfield project, que pode ser caracterizado como o investimento em uma estrutura já existente em que o comprador pode ou não a alterar por completo (MEYER; ESTRIN, 1998).

A partir destes conceitos, verifica-se que, na contextualização das operações de F\&A decorrentes do IED no Brasil, esse tipo de investimento pode ser inicialmente observado com o crescimento da entrada de IED no MERCOSUL na década de 1990, cujo principal objetivo era realizar operações de F\&A. Além disso, o Plano Real foi um dos responsáveis por proporcionar uma retomada dos fluxos de investimento para a economia (SCHERER, 2004; BONELLI, 2000). Scherer (2004) afirma que "o investimento direto estrangeiro passou a ser visto como aquele elemento capaz de dinamizar a economia brasileira (...) tendo como vantagens o acesso à tecnologia de ponta, ao financiamento externo e aos canais de comercialização externos".

Pode-se dizer que o IED, ao longo da década de 1990, causou uma internacionalização da produção diferente de outros países que estavam realizando o mesmo processo, uma vez que o Brasil não ganhou uma maior presença no cenário mundial, seja em forma de produtos ou em forma de empresas e acabou se tornando mais dependente de produtos importados para poder realizar sua produção (SARTI; LAPLACE, 2003).

\section{PERFIL DAS F\&A NO BRASIL NOS ANOS 2000}

Para se analisar o perfil do processo de F\&A no Brasil, é importante entender o contexto que levou à atual situação. A abertura da economia brasileira, com início no mandato de Fernando Collor pelo Programa Nacional de Desestatização, prosseguiu durante o governo de Itamar Franco e foi intensificado por Fernando Henrique Cardoso. Tal ação acabou barateando os custos dos insumos e dos bens de capital importados, além de estimular a concorrência entre os produtos nacionais e internacionais (BORGES; COSTA, 2008).

Em 1994, foi instituído o Plano Real, com medidas voltadas para a estabilização de preços na economia. Este período foi marcado pela remoção das restrições ao ingresso de capital estrangeiro em diversos setores, com destaque para o capital financeiro, o que acabou favorecendo as F\&A no investimento externo direto. Em suma, os anos 1990 foram marcados pelo aumento significativo do processo de F\&A, onde essa estratégia ganhou destaque movido pelas privatizações principalmente das empresas estatais, cujo objetivo era diminuir a dívida pública. 
A Tabela 1 mostra a quantidade total de F\&A realizadas no Brasil entre 2000 e 2015, e ilustra a participação das operações domésticas e do tipo cross border. Nota-se que, no período analisado, houve um aumento quantitativo significativo do total das operações de F\&A praticadas no país (cerca de 119\%). O início da década foi marcado pelo aumento desse processo. Seguindo a tendência mundial, os anos de 2001 e 2002 ficaram caracterizados por uma queda na quantidade de F\&A realizadas, mantendo-se estável em quantidade no ano de 2003. Em 2004, o processo foi retomado e se manteve crescente até 2007. Em 2008, a ocorrência da crise internacional com origem na economia norte-americana impactou esse tipo de operação, principalmente em 2009, que foi o ano em que o Brasil foi mais influenciado economicamente por esse acontecimento. Todavia, após esse período, o aumento das operações de F\&A foi alavancado, mantendo-se estável desde 2011.

Tabela 1: Fusões e Aquisições Domésticas e Cross Border, 2000-2015

\begin{tabular}{cccccc}
\hline \multirow{2}{*}{ Ano } & \multicolumn{2}{c}{ Doméstica } & \multicolumn{2}{c}{ Cross Border } & \multirow{2}{*}{ TOTAL } \\
\cline { 2 - 4 } & No. & $\%$ & No. & $\%$ & 353 \\
2000 & 123 & 34,8 & 230 & 65,2 & 340 \\
2001 & 146 & 42,9 & 194 & 57,1 & 227 \\
2002 & 143 & 62,9 & 84 & 37,1 & 230 \\
2003 & 116 & 50,4 & 114 & 49,6 & 299 \\
2004 & 100 & 33,4 & 199 & 66,6 & 363 \\
2005 & 150 & 41,3 & 213 & 58,7 & 473 \\
2006 & 183 & 38,6 & 290 & 61,4 & 699 \\
2007 & 351 & 50,2 & 348 & 49,8 & 663 \\
2008 & 379 & 57,1 & 284 & 42.9 & 454 \\
2009 & 219 & 48,2 & 235 & 51,8 & 726 \\
2010 & 333 & 45,8 & 393 & 54,2 & 817 \\
2011 & 410 & 50,1 & 407 & 49,9 & 816 \\
2012 & 342 & 41,9 & 474 & 58,1 & 796 \\
2013 & 365 & 45,8 & 431 & 54,2 & 818 \\
2014 & 331 & 40,4 & 487 & 59,6 & 773 \\
2015 & 265 & 34,2 & 504 & 65,8 & \\
\hline
\end{tabular}

Fonte: Elaboração própria a partir de dados de KPMG (2015).

Quando se analisa o tipo de F\&A envolvida, verifica-se que predomina os procedimentos que envolvem empresas de diferentes países, pois, em média, as estratégias do estilo cross border representaram $56 \%$ do total de operações realizadas. As exceções foram os anos de 2002 e 2008, em que as operações domésticas superaram as do tipo cross border. Tais resultados podem ser associados ao período de incerteza na economia brasileira em 2002, em decorrência da eleição presidencial e instabilidade macroeconômica decorrente (inflação elevada e oscilação cambial), e, em 2008, ao contexto de crise internacional, o que desmotivou as operações envolvendo agentes estrangeiros. 
Em termos setoriais, de acordo com o Quadro 1, é possível afirmar que os setores de tecnologia da informação; alimentos, bebidas e fumo; companhias energéticas; telecomunicações e mídia foram os que mais realizaram processos de F\&A no período de 2000 a 2015. Destaca-se o setor da tecnologia da informação, o qual realizou aproximadamente 95\% de seus processos de F\&A dentro do período analisado, tornando-se assim o principal setor no quesito quantidade no Brasil (KPMG, 2015b).

Quadro 1: Quantidade de F\&A por setor acumulado, 2000-2015²

\begin{tabular}{|c|c|c|c|}
\hline Posição & Setores & № de Transações & $\begin{array}{c}\text { Participação das F\&A no } \\
\text { Período (\%) }\end{array}$ \\
\hline 10 & Tecnologia da Informação & 1060 & 11,9 \\
\hline 20 & Alimentos, Bebidas e Fumo & 700 & 7,9 \\
\hline 3으 & Companhias Energéticas & 472 & 5,3 \\
\hline 40 & Telecomunicação e Mídia & 404 & 4,5 \\
\hline 50 & Publicidade e Editoras & 368 & 4,2 \\
\hline 60 & Instituições Financeiras & 361 & 4,1 \\
\hline 70 & Serviços para Empresas & 358 & 4,0 \\
\hline 80 & Produtos Químicos e Petroquímicos & 321 & 3,6 \\
\hline 9o & Imobiliário & 293 & 3,3 \\
\hline 100 & Empresas de Internet & 292 & 3,3 \\
\hline
\end{tabular}

Fonte: Elaboração própria a partir de dados de KPMG (2015).

Considerando os dados apresentados, pode-se dizer que, no período analisado, o perfil que melhor representa as F\&A no Brasil envolve ações do estilo cross border, pertencentes ao setor de tecnologia da informação, embora estas totalizem apenas $12 \%$ das operações de $F \& A$. Isto mostra que as $F \& A$ no Brasil são diversificadas em vários aspectos, dificultando a elaboração de um modelo a se seguir ou um padrão que represente melhor a totalidade.

\section{ANÁLISE DOS DADOS}

Observando a origem dos países que realizam investimentos diretos no país, percebe-se que os Estados Unidos não é o maior investidor no Brasil. De acordo com a Tabela 2, que mostra o percentual de IED juntamente com as operações de F\&A do estilo cross border, que representam entrada e/ou saída de capital, os Países Baixos representaram $20 \%$ de todo investimento feito, enquanto equivalem a menos de $2 \%$ das

\footnotetext{
2 Algumas classificações utilizadas pela KPMG foram modificadas com o passar dos anos. Por exemplo, apenas em 2007 foi criado o setor imobiliário, assim como em 2008 foi estabelecido o setor educação, sendo que estes ocupam respectivamente a 12a e a 18ㅁ posição em termos de quantidade de F\&A quando analisado o período desde o Plano Real (1996) até 2015. O Quadro 1 mostra que o setor imobiliário está entre os mais movimentados, mesmo desconsiderando oito anos de inexistência.
} 
F\&A ocorridas em 2015, enquanto os Estados Unidos foram os responsáveis pelo maior número de operações de F\&A (quase 40\%), porém representaram 11,5\% do IED no Brasil.

Tabela 2: F\&A Crossborder e IED no Brasil. 2005-2015³

\begin{tabular}{ccccccc}
\hline \multirow{2}{*}{ País } & \multicolumn{3}{c}{ Fusões e Aquisições (\%) } & \multicolumn{3}{c}{ Investimento Estrangeiro Direto (\%) } \\
\cline { 2 - 7 } & 2005 & 2010 & 2015 & 2005 & 2010 & 2015 \\
\hline Estados Unidos & 41,8 & 40,3 & 39,5 & 21,1 & 11,7 & 11,5 \\
Outros & 23,5 & 27,3 & 25,4 & 38,4 & 42,6 & 29,4 \\
França & 10,6 & 7,5 & 7,0 & 6,6 & 6,6 & 4,9 \\
Alemanha & 7,1 & 5,1 & 4,8 & 6,3 & 1,0 & 6,0 \\
Japão & 4,1 & 2,4 & 5,1 & 3,5 & 4,8 & 5,0 \\
Suíça & 3,5 & 4,1 & 4,1 & 1,6 & 12,3 & 1,9 \\
Grã-Bretanha & 2,9 & 5,5 & 5,6 & 0,7 & 2,0 & 2,8 \\
Espanha & 2,4 & 3,4 & 2,4 & 5,5 & 2,9 & 11,3 \\
Países Baixos & 2,4 & 2,7 & 1,9 & 14,6 & 12,7 & 20,0 \\
Itália & 1,2 & 0,7 & 3,4 & 1,6 & 0,6 & 3,0 \\
\hline
\end{tabular}

Fonte: Elaboração própria a partir dos dados da KPMG e do BACEN.

Esse comportamento dos Países Baixos pode ser explicado pelo fato das firmas lá instaladas visualizarem oportunidades de médio e longo prazo no Brasil, trazendo grande parte de suas corporações para o território nacional, como é o caso da abertura da NIAE (Agência Neerlandesa de Investimentos Estrangeiros) em São Paulo. Porém é importante ressaltar que a Holanda atua como um criador de capacidade produtiva, ou seja, suas movimentações são majoritariamente de natureza greenfield, o que explica a baixa quantidade de $F \& A$.

Analisando como as F\&A se comportam em relação ao IED, é possível notar, por meio do Gráfico 1, o comportamento similar com relação à movimentação das curvas. A correlação existe entre essas variáveis é de 0,94 , mostrando assim que o comportamento de uma curva acaba se identificando com a outra.

\footnotetext{
${ }^{3}$ Os dados referentes ao IED são classificados pelo BACEN como recursos aplicados diretamente no capital de empresas do País, sendo que se elimina reinvestimento de lucros.
} 


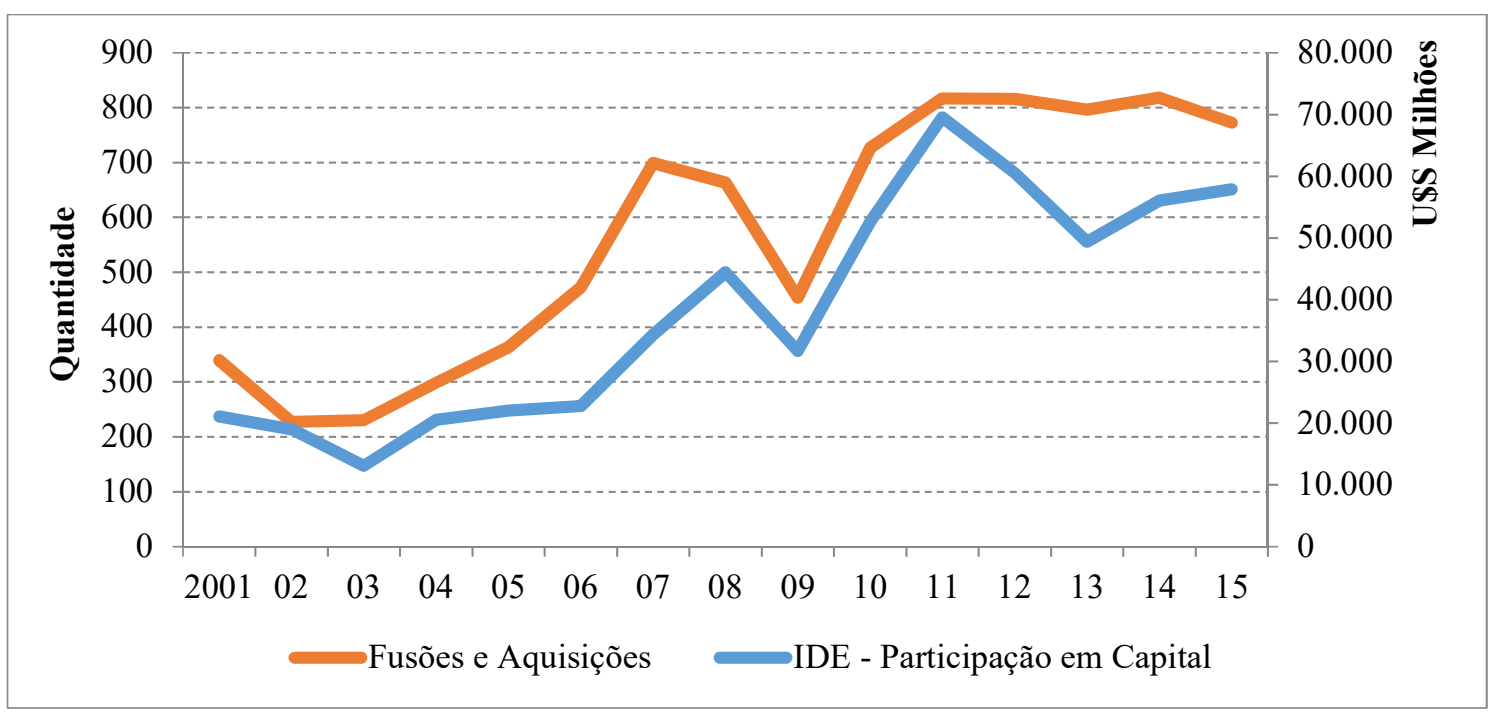

Gráfico 1: Fusões e Aquisições x IDE em Participação de Capital, 2001-2015

Fonte: Elaboração própria a partir dos dados da KPMG e BACEN.

Em termos setoriais, observa-se que o comportamento de desnacionalização não possui os mesmos parâmetros em todos os setores. Observando a Tabela 3, que mostra as F\&A do estilo cross border, juntamente com as operações que representam a entrada de capital, não necessariamente os maiores setores em quantidade de operações de F\&A são os mais internacionalizados.

Analisando o intervalo de três em três anos, com o objetivo de conseguir captar tendência de comportamentos, observa-se que os setores que apresentam um alto percentual de internacionalização não necessariamente estão passando por um processo de desnacionalização. O setor de produtos químicos e petroquímicos, por exemplo, apresenta um alto grau de internacionalização no período observado, sendo que, somente a partir de 2012, demonstrou um processo de desnacionalização.

Os principais setores em termos de F\&A apresentam um processo de internacionalização elevado (superior a 50\%) no ano de 2015, porém, quando se observa quanto desses processos representam desnacionalização, nota-se que os valores são menos significantes. Desta forma, é possível afirmar que estes segmentos estão passando por um processo de internacionalização, mas não por desnacionalização.

Para analisar como a entrada de capital está impactando o processo de F\&A é importante conseguir captar a sensibilidade existente nas movimentações seja no processo como um todo, ou apenas focalizando nas estratégias que envolvem a entrada de capital, para assim mostrar quanto um aumento de IED irá causar de aumento na utilização de $F \& A$. 
Tabela 3: F\&A Cross Border por Setor, 2006-20154

\begin{tabular}{ccccc|cccc}
\hline Setor/Ano & \multicolumn{4}{c}{ Cross Border (\%) } & \multicolumn{5}{c}{ Cb1+Cb4+Cb5 (\%) } \\
& $2006^{5}$ & 2009 & 2012 & 2015 & 2006 & 2009 & 2012 & 2015 \\
\hline Tecnologia da Informação & 65,2 & 39,7 & 63,5 & 50,4 & 54,3 & 32,8 & 50,0 & 47,6 \\
Alimentos, Bebidas e Fumo & 65,1 & 66,7 & 60,9 & 74,2 & 48,8 & 30,8 & 47,8 & 36,9 \\
Companhias Energéticas & 60,7 & 52,6 & 33,3 & 82,8 & 34,4 & 10,5 & 16,7 & 72,4 \\
Serviços para Empresas & 58,8 & 11,1 & 70,8 & 65,8 & 58,8 & 11,1 & 66,2 & 53,9 \\
Telecomunicação e Mídia & 53,6 & 56,5 & 63 & 66,7 & 50,0 & 47,8 & 59,3 & 61,9 \\
Publicidade e Editoras & 47,4 & 45,5 & 54,2 & 53,8 & 42,1 & 40,9 & 37,5 & 50,0 \\
Instituições Financeiras & 81 & 45,5 & 50 & 72,7 & 47,6 & 31,8 & 41,7 & 50,0 \\
Produtos Químicos e Petroquímicos & 61,9 & 77,8 & 83,3 & 90,9 & 38,1 & 11,1 & 61,1 & 90,9 \\
Imobiliário & - & 47,8 & 33,3 & 37,5 & - & 43,4 & 21,2 & 31,3 \\
Empresas de Internet & - & - & 78,6 & 50,0 & - & - & 73,2 & 45,7 \\
\hline
\end{tabular}

Fonte: Elaboração própria a partir dos dados da KPMG.

Devido à escassa disponibilidade de dados, o que não permite a estimação de modelos empíricos robustos, o formato utilizado para captar a sensibilidade das F\&A ao IDE será o cálculo da elasticidade, definida como os efeitos da variação no IED sobre as operações de $F \& A$.

Analisando a Tabela 4, que mostra a elasticidade ${ }^{6}$ das F\&A com relação ao IED entre 2002 até 2015, é possível perceber que as fusões e aquisições totais são relativamente sensíveis ao IDE, com uma média de 1,27 no período analisado. Além disso, apenas três anos apresentam valores negativos, sendo dois deles (2008 e 2015) explicados por questões macroeconômicas internacionais, que acabaram afetando o mercado nacional. Dando enfoque apenas às operações crossborder, nota-se que os valores apresentam uma maior variação em relação à comparação anterior com uma média de 1,46, mostrando assim que o IED tem um efeito maior na variação das $F \& A$ cross border do que as intervenções totais.

\footnotetext{
${ }^{4}$ Seguindo a classificação feita pela KPMG, à soma entre as operações de estilo cross border do tipo um, quatro e cinco representam transações envolvendo a entrada de capital estrangeiro no Brasil, enquanto a soma dos modelos três e quatro representa a saída de capital estrangeiro do país. Levando em consideração que a presente pesquisa foca no possível processo de desnacionalização, somente a entrada de capital é analisada.

${ }^{5}$ A análise começa no ano de 2006, ano de divulgação das divisões existentes dentro das F\&A cross border pela KPMG. Antes dessa data, só é possível classificar as operações em domésticas ou cross border.

${ }^{6}$ A elasticidade foi calculada por meio da seguinte expressão: $E=\% \Delta F \& A / \% \Delta I E D$.
} 
p. 67 - Fusões e aquisições no Brasil e a desnacionalização da produção nos anos 2000

Tabela 4: Elasticidade das F\&A ao Investimento Direto Estrangeiro, 2002-2015.

\begin{tabular}{cccc}
\hline Ano & $\begin{array}{c}\text { F\&A } \\
\text { IDE }\end{array}$ & $\begin{array}{c}\text { Cross Border } \\
\text { IDE }\end{array}$ & $\begin{array}{c}\text { Cb1+Cb4+Cb5 } \\
\text { IDE }^{7}\end{array}$ \\
\hline 2002 & 3,29 & 5,61 & - \\
2003 & $-0,04$ & $-1,15$ & - \\
2004 & 0,53 & 1,31 & - \\
2005 & 2,93 & 0,96 & - \\
2006 & 9,20 & 10,98 & 4,49 \\
2007 & 0,94 & 0,39 & 0,62 \\
2008 & $-0,17$ & $-0,62$ & $-0,84$ \\
2009 & 1,10 & 0,60 & 0,49 \\
2010 & 0,91 & 1,02 & 1,18 \\
2011 & 0,39 & 0,11 & 0,31 \\
2012 & 0,01 & $-1,27$ & $-2,04$ \\
2013 & 0,13 & 0,49 & 0,56 \\
2014 & 0,20 & 0,96 & 0,71 \\
2015 & $-1,66$ & 1,05 & 0,98 \\
\hline
\end{tabular}

Fonte: Elaboração própria a partir dos dados da KPMG e do BACEN.

Observa-se que as F\&A que realizam a entrada de capital não são muito sensíveis ao IED, com uma elasticidade média de 0,64. Analisando os valores negativos, pode-se dizer que essas operações são impactadas por quedas no investimento, uma vez que grande parte dessa entrada de capital é para sustentar operações já existentes. Ou seja, o aumento do IED acaba não criando capital na mesma proporção que a diminuição do investimento causa em relação a sua destruição.

Tabela 5: Média das Elasticidades das F\&A por Setor, 2006- 2015.

\begin{tabular}{cccc}
\hline \multirow{2}{*}{ Setor } & \multicolumn{3}{c}{ Média das Elasticidades } \\
\cline { 2 - 4 } & F\&A & Cross Border & Cb1+Cb4+Cb5 \\
\hline Tecnologia da Informação & 0,46 & $-0,12$ & $-0,13$ \\
Alimentos, Bebidas e Fumo & 0,25 & 0,42 & 0,74 \\
Companhias Energéticas & 0,12 & 1,37 & 1,73 \\
Serviços para Empresas & 2,15 & 32,67 & 29,09 \\
Telecomunicação e Mídia & 6,44 & 7,41 & 6,69 \\
Publicidade e Editoras & $-0,07$ & 0,58 & $-0,88$ \\
Instituições Financeiras & $-0,04$ & 0,13 & 0,11 \\
Produtos Químicos e Petroquímicos & $-0,62$ & 0,06 & 1,67 \\
Imobiliário & 0,58 & 0,24 & $-0,07$
\end{tabular}

\footnotetext{
7 É importante salientar a criação do sistema de classificação das operações de fusões e aquisições cross border em quatro formas diferentes inicialmente no ano de 2005, e a adição da Cb5 em 2006, devido a isso sua análise possui uma série temporal menor.
} 
Fonte: Elaboração própria a partir dos dados da KPMG e do BACEN.

A análise das elasticidades por setor, conforme mostra a Tabela 5, indica que grande parte deles não apresenta alta sensibilidade ao IED realizado. Setores como tecnologia da informação e imobiliário são inelásticos ao IED em determinadas situações. Telecomunicação e mídia juntamente com serviços para empresas são os mais sensíveis ao investimento externo devido ao fato de que suas operações em entradas de capital representam uma grande parcela das operações feitas.

O setor de serviços para empresas apresenta uma média alta, em grande parte movimentada pelo crescente no mercado que ocorreu a partir de 2010 , onde suas operações de F\&A apresentaram um crescimento de $72 \%$, as crossborder de $850 \%$ e as operações responsáveis por desnacionalizar a produção de $750 \%$ quando comparado ao ano anterior. Isso pode ser explicado pelo fato de que esse setor apresenta firmas que realizam pesquisas de consultoria, um ramo que apresenta crescimento em momentos de crise nacional.

Em suma, é possível observar que o IED acaba sendo mais eficaz em grande parte dos setores para realizar a internacionalização, e não a desnacionalização da produção. Isso ocorre em grande parte porque empresas de grande capital tendem a não possuir uma única nacionalidade. Assim, parte do investimento acaba sendo para as empresas expandirem seu mercado.

Também se percebe que o fato de um país investir de forma significativa no Brasil não significa que ele está entre os líderes de operações de $F \& A$, uma vez que o investimento pode ser feito, como já comentado, em projetos com uma cadeia produtiva ainda inexistente (greenfield). Países, como a Holanda, realizam investimento para fortalecer firmas e marcas já existentes, como a cervejaria Heineken ou o atacadista Makro.

Além disso, observa-se que os setores analisados, juntamente com o processo de F\&A como um todo, acabam sendo pouco sensíveis ao aumento do IED, uma vez que suas elasticidades apresentadas são inferiores a denominação "unitária". Com isso espera-se que um aumento no IED tenha um impacto nas F\&A, porém um aumento nas F\&A não necessariamente causa uma desnacionalização da produção.

\section{CONSIDERAÇÕES FINAIS}

Considerando os aspectos teóricos e os dados analisados, verifica-se que os estudos associados às operações de F\&A ainda são incipientes no país, sendo que tal operação se tornou popular após o Plano Real. Ainda é difícil englobar a atividade em uma metodologia mais robusta em termos de realização de pesquisas empíricas, visto a disponibilidade temporal restrita dos dados. Além disso, as empresas que realizam as divulgações de dados não apresentam sua metodologia, dificultando a compreensão.

Devido a isto, procurou-se trazer alguns conceitos considerados importantes para o entendimento do tema, mostrando que o maior benefício das F\&A é a possibilidade de 
eliminar ou reduzir os riscos gerais de entrada de uma empresa em determinado mercado.

Um perfil nacional das F\&A foi elaborado no presente trabalho, verificando que essa ação pode ser considerada diversificada, uma vez que suas características não representam uma parcela significativa do todo. Porém vale ressaltar que as F\&A do tipo cross border ligado ao setor de tecnologia de informação é o modelo mais representativo do tipo de operação de ocorre na economia brasileira no período analisado.

As informações levantadas pelo artigo sugerem que o processo de F\&A é acompanhado por uma entrada de IED na nação. Levando em consideração que a maior parte do capital investido é destinado a F\&A e grande parte destas representa a entrada de empresas estrangeiras no país, esperava-se que tais operações causassem desnacionalização da produção, sendo essa a hipótese inicial do trabalho.

Dos setores analisados, apenas um apresenta uma média de operações de entrada de capital estrangeiro relativamente baixo, que é o imobiliário. Quando se confronta os dados da desnacionalização com os de investimento, é possível observar que mesmo os setores que estão apresentando um processo de desnacionalização no período analisado não apresentam uma sensibilidade ao IED.

Observando as operações de F\&A no todo, nota-se que o aumento do IED acaba não influenciando de forma significativa as operações de entrada de capital. A elasticidade $(0,64)$ demostra uma sensibilidade baixa existente sobre essa ação, porém, quando se observa as F\&A do estilo cross border como um todo, têm-se um resultado mais satisfatório $(1,46)$.

Conclui-se que o aumento no IED tem uma influência maior nos aspectos de internacionalização do que na desnacionalização, uma vez que o IED feito em formato de raiz tende em um primeiro momento fortalecer empresas localizadas no território brasileiro para poder permitir a expansão de seu mercado sobre a fronteira.

Em suma, considerando que o IED tem por objetivo realizar em parte operações de F\&A e as operações de entrada de capital não estão apresentando uma sensibilidade significativa a esse fenômeno, não é possível afirmar que um aumento do IED cause maior desnacionalização.

Com isso, nota-se uma reversão do processo citado por Scherer (2004) iniciado no momento da abertura cambial, onde o IED tinha uma enorme influência sobre as F\&A e as aplicações feitas em capital não existente era algo minoritário. Atualmente, observase um investimento mais diversificado, o que tende a ser melhor para a economia, pois uma nação que recebe todo seu investimento em operações de F\&A tem dificuldades de crescer, principalmente pelo fato desse investimento não criar ou aumentar a capacidade produtiva no curto prazo, sendo que se o governo precisar estimular algum modelo de investimento, o mais adequado seria o investimento em processos produtivos ainda não existentes, ou seja, o investimento greenfield.

\section{REFERÊNCIAS}


AMAL, M.; SEABRA, F. Determinantes do Investimento Direto Externo (IDE) na América Latina: Uma Perspectiva Institucional. Revista EconomiA, Brasília (DF), v.8, n.2, p.231-247, maio/agosto 2007.

APEX BRASIL. Agência Brasileira de Promoção das Exportações e dos Investimentos. Ministério das Relações Exteriores. Disponível em: http://www.apexbrasil.com.br/o-quee-ied. Acessado em: 05 set. 2017.

BCB. BANCO CENTRAL DO BRASIL. Série Histórica dos Fluxos de Investimento Direto Distribuição por País ou por Setor. Disponível em: http://www.bcb.gov.br/ptbr/paginas/default.aspx Acessado em: 12 fev. 2016.

BONELLI, R. Fusões e Aquisições no MERCOSUL.IPEA (Instituto de Pesquisa Aplicada) Texto de Discussão 0718, Rio de Janeiro. Abril. 2000.

BORGES, A.C.G.; COSTA, V.M.H.M. Fusões e Aquisições: caracterização e evolução no Brasil no período de 1992 a 2007. Anais do XXVIII Encontro Nacional de Engenharia da Produção: A integração de cadeias produtivas com a abordagem da manufatura sustentável. Rio de Janeiro, v. 13. 2008.

CASTRO, P. G.; FERNANDES, E. A.; CAMPOS, A. C. Os Determinantes do Investimento Direto Estrangeiro no Brasil e no México: Uma Análise Empírica. Anais do XLI Encontro Nacional de Economia. No. 118. ANPEC (Associação Nacional do Centro de PósGraduação em Economia), 2014.

CORDEIRO, M. The Seventh M\&A Wave. 2015. Disponivel em: http://www.camaya.com.br/site/es/insights/52/2014/09/the seventh m\&a wave.

Acessado em: 31 ago. 2015

HITT, A. M. Estratégias de Aquisição e Reestruturação. In: HITT, A. M. Administração Estratégica: Competitividade e Globalização. Irlanda; Cengage Learning, 2008. p. 180-207.

KPMG. Pesquisa de Fusões e Aquisições 2005 - 4 을 trimestre: Espelho das transações realizadas no Brasil. São Paulo. 2006. 32p

KPMG. Pesquisa de Fusões e Aquisições 2008 - 4을 trimestre: Espelho das transações realizadas no Brasil. São Paulo. 2009. 32p

KPMG. Pesquisa de Fusões e Aquisições 2009 - 40 trimestre: Espelho das transações realizadas no Brasil. São Paulo. 2010. 31p

KPMG. Pesquisa de Fusões e Aquisições 2010 - 4으 trimestre: Espelho das transações realizadas no Brasil. São Paulo. 2011. 31p

KPMG. Pesquisa de Fusões e Aquisições 2012 - 40 trimestre: Espelho das transações realizadas no Brasil. São Paulo. 2013. 38p

KPMG. Pesquisa de Fusões e Aquisições 2013 - 4 timestre: Espelho das transações realizadas no Brasil. São Paulo. 2014. 40p

KPMG. Pesquisa de Fusões e Aquisições 2014 - 40 trimestre: Espelho das transações realizadas no Brasil. São Paulo. 2015a. 40p 
p. 71 - Fusões e aquisições no Brasil e a desnacionalização da produção nos anos 2000

KPMG, Pesquisa de Fusões e Aquisições 2015 - 1올 semestre: Espelho das transações realizadas no Brasil. São Paulo. 2015b. 49p

KPMG, Pesquisa de Fusões e Aquisições 2015 - 2o semestre: Espelho das transações realizadas no Brasil. São Paulo. 2016. 48p

KUPFER, D. Diversificação, competências e coerência produtiva. In: KUPFER, D.; HASENCLEVER, L. Economia Industrial: Fundamentos Teóricos e Práticos no Brasil.6a ed. Rio de Janeiro: Elsevier, 2002.

MAZARS; MARCCUS PARTNERS.M\&A in Fast Growing Countries: Traps and Structuring Opportunities. A study encompassing the BRICS and next 10 emerging or emerged countries, Paris. 2013.

MEYER, K. E.; ESTRIN, S. Brownfield entry in emerging markets. Journal of International Business Studies, p. 575-584, 2001.

PwC. PriceWaterhouseCoopers. Fusões e Aquisições no Brasil. Disponível em http://www.pwc.com.br/pt/publicacoes/servicos/fusoes-aquisicoes.html. Acessado em: 9 de set. 2015.

RODRIGUES, P. C. S. F. N. Fusões e Aquisições Internacionais e Investimentos de Raiz: Determinantes Macroeconómicos e Efeitos sobre o Crescimento. Tese de Doutoramento em Ciências Empresariais, Universidade do Porto, 2009.

SALGADO, R. M. Uma análise da evolução os processos de fusões e aquisições no Brasil no período de 1994 a 2009. Tese de Mestrado, Universidade Federal de Sergipe, São Cristóvão, Sergipe, 2010.

SANDRONI, P. Dicionário de Economia do Século XXI. 8. ed. Rio de Janeiro: Record, 2005.

SARTI, F.; LAPLACE, M. F. O investimento direto estrangeiro e a internacionalização da economia brasileira nos anos 1990.Economia e Sociedade, v.11, n.1, p.18, 2003.

SCHERER, A. L. F. Investimento Direto Estrangeiro, Fusões e Aquisições e Desnacionalização da Economia Brasileira: Um Balanço da Década do Plano Real. Indicadores Econômicos FEE, Porto Alegre, v.32, n.2, p.107-128, ago. 2004.

SCHMIDT, J. A. Businnes Perspective on Mergers and Acquisitions.In: SCHMIDT, J. A. Making Mergers Work. Alexandria, VA: Society for Huma Resource. 2002

UNCTAD. UNITED NATIONS CONFERENCE ON TRADE AND DEVELOPMENT. World Investment Report 2015: Reforming International Investment Governance. Nova York e Genebra, Nações Unidas. 2015. 